\title{
Nutritional management of very low birth weight at a hospital center of Antananarivo
}

\section{Zoly Nantenaina Ranosiarisoa ${ }^{1 *}$, Mirana Zita Ramananirina ${ }^{2}$, Rosa Lalao Tsifiregna $^{3}$, Lovaniaina Ravelomanana ${ }^{2}$, Noëline Ravelomanana ${ }^{2}$}

\begin{abstract}
${ }^{1}$ Department of Mother and Child, Neonatal Unit, Obstetrical and Gynecologic Hospital Center of Befelatanana, Antananarivo Madagascar

${ }^{2}$ Department of Mother and Child, Mother and Child Universitary Hospital Center Ambohimiandra, Antananarivo Madagascar

${ }^{3}$ Department of Mother and Child, Pediatric et Neonatal Unit of Soavinandriana Hospital Center, Antananarivo Madagascar
\end{abstract}

Received: 13 October 2019

Accepted: 06 November 2019

\section{*Correspondence:}

Dr. Zoly Nantenaina Ranosiarisoa,

E-mail: zranosi@hotmail.fr

Copyright: $\odot$ the author(s), publisher and licensee Medip Academy. This is an open-access article distributed under the terms of the Creative Commons Attribution Non-Commercial License, which permits unrestricted non-commercial use, distribution, and reproduction in any medium, provided the original work is properly cited.

\section{ABSTRACT}

Background: Very low birth weight (VLBW) new-borns represent vulnerable group. The lower the birth weight, the higher the mortality rate. The objective of this study was to describe the nutritional management of VLBW new-borns and to determine their hospital outcome.

Methods: A retrospective cohort study was carried out during 24 months in a hospital center of Antananarivo. All newborns weighing less than $1500 \mathrm{~g}$ at birth and admitted to neonatal resuscitation service were included.

Results: Of the 577 newborns admitted during this period, 48 were retained as very low birth weight. All had less than to 37 gestational age. New-borns less than or equal to 32 gestational age had a 4.02 -fold risk of dying. VLBW with a birth weight less than $1,000 \mathrm{~g}$ were 2.12 times more likely to die than those between 1,000 and 1,499 g. The use of artificial milk was neither associated with the onset of digestive intolerance nor associated with VLBW early outcome.

Conclusions: Hospital nutritional management of VLBW requires specific and delicate care. Breast milk is ideal for the newborn. But if it is not available immediately, the alternative that is not disadvantageous is artificial milk.

Keywords: Care, Mortality, Nutrition, Prematury, Very low birth weight

\section{INTRODUCTION}

Any neonate with a birth weight less than $1,500 \mathrm{~g}$ regardless of gestational age is defined as having a very low birth weight (VLBW) according to the WHO ${ }^{1}$ Birth weight is a major determinant of neonatal mortality and infant morbidity. ${ }^{2,3}$ The lower the birth weight, the higher the mortality rate. ${ }^{3}$ Prematurity is in most cases the etiology of VLBW, the immaturity of all premature systems explains the difficulty of its management. One of the immature systems is the digestive system. Often, in front of the impossibility of initiating enteral feeding, parenteral nutrition must be used. Parenteral nutritional solutions formulated with proteins, carbohydrates and lipids conveyed through a central catheter and covering the nutritional needs of newborns are used from the first days to avoid protein-energy deficiency. ${ }^{4}$

But this parenteral nutrition is not available in most developing countries like Madagascar. ${ }^{5}$ 
However, the short- and long-term consequences of low birth weight greatly depend on the quality of initial nutritional management, in the first few days of life, and the quality of growth during this critical period. ${ }^{6}$

Nutritional management of VLBW is therefore a challenge in our country; which prompted us to evaluate the digestive situation of VLBW new-borns in one of the hospitals of Madagascar.

The objective of this study was to describe the nutritional management of VLBW new-borns and their hospital outcome.

\section{METHODS}

The study was conducted in the pediatric and neonatology department of a hospital of Antananarivo. It is a retrospective cohort over a 24 -month period from January $1^{\text {st }}, 2016$ to December $31^{\text {st }}, 2017$.

All newborns weighing less than $1500 \mathrm{~g}$ at birth and admitted to neonatal resuscitation service were included. Newborns less than $1500 \mathrm{~g}$ with visible congenital malformations, those whose records were incomplete or unusable, those who were transferred to another department, and newborns who had been discharged for medical advice were excluded. Sampling was exhaustive. The duration of follow-up was represented by stays in hospital.

The parameters analyzed were the characteristics of newborns (gestational age, Apgar index, birth weight, gender, place of birth: inborn for newborns delivered at the hospital, or outborn for others, the mode of delivery.

On the gastrointestinal level, the variables studied were: the date of onset of feeding, the date of onset of food autonomy which corresponds to the end date of the infusion, the type of milk: at the beginning and at the end of the hospitalization, the presence or absence of digestive intolerance: dirty residue, bloody or abundant.

\section{Statistical analysis}

Data were collected from patients' individual records and medical records, were captured and analyzed with the epi info 7 software. To analyze the risk factors associated with the child's death, we calculated the relative risk (RR) with its $95 \%$ confidence interval. An RR greater than 1 means that the variable analyzed was a risk factor associated with death. This association is significant if the $95 \%$ confidence interval of RR excludes the number 1. The link between two variables is significant if $p<$ 0.05 .

\section{RESULTS}

During the study period, 577 new-borns were admitted to the service, including 51 with a birth weight of less than
$1500 \mathrm{~g}$, for a hospital prevalence of $8.8 \%$. With three excluded cases, the final sample was 48 . Table 1 shows the characteristics of the sample at admission. A slight female predominance (sex ratio 0.77) was found. The majority of new-borns were born inborn. All neonates were premature with an average gestational age of $30.14 \pm 3.3$. Most VLBW had a birth weight greater than $1,000 \mathrm{~g}$. The average weight was $1120 \pm 250 \mathrm{~g}$ (Figure 1).

Table 1: Characteristics of the sample at admission.

\begin{tabular}{|llll|}
\hline Factor & N & $\%$ & A verage \pm CI \\
\hline Sex & & & \\
\hline Male & 21 & 43.75 & \\
\hline Female & 27 & 56.25 \\
\hline Place of delivery & & & \\
\hline Inborn & 38 & 79.2 & \\
\hline Out born & 10 & 20.8 & \\
\hline Gestational age & & & \\
\hline$<28$ & 14 & 29.2 & \\
\hline $28-32$ & 17 & 35.4 & \\
\hline $32-37$ & 17 & 35.4 & \\
\hline Delivery mode & & & \\
\hline Vaginal delivery & 30 & 62.5 & \\
\hline Caesarean delivery & 18 & 37.5 & \\
\hline Weight at birth(g) & & & \\
\hline$<1000$ & 13 & 27.1 & \multirow{2}{*}{$1120 \pm 250$} \\
\hline $1000-1500$ & 35 & 72.9 \\
\hline Apgar index & & \\
\hline$<7$ & 14 & 29.17 \\
\hline$\geq 7$ & 29 & 60.41 \\
\hline Unknown & 5 & 10.42 \\
\hline
\end{tabular}

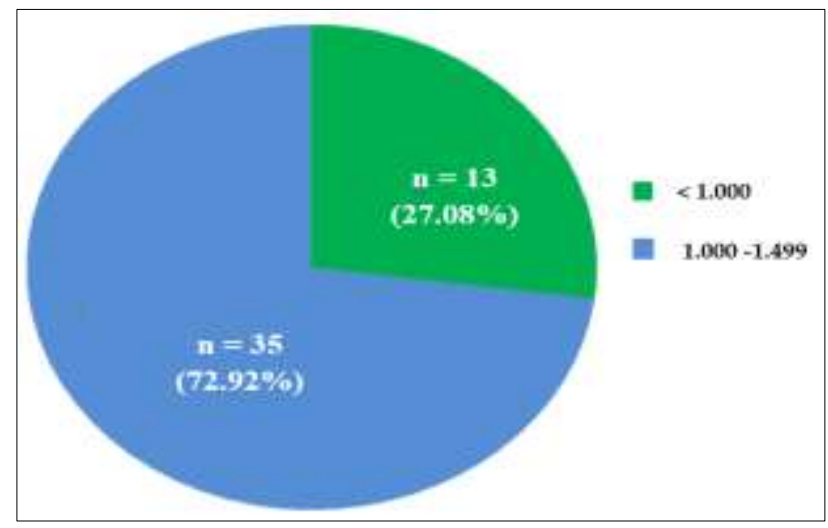

Figure 1: Distribution of new-borns by birth weight (in grams).

Table 2 presents the nutritional management. Almost half of the new-borns had started enteral feeding on day 2 of life. Food autonomy was acquired on average on the fourth day. A predominance of artificial milk was observed during the first feeding $(n=20)$. $43 \%$ of newborns were able to benefit from exclusive breastfeeding at the discharge. 
Table 2: Nutritional management.

\begin{tabular}{|c|c|c|c|}
\hline Factors & $\mathbf{N}$ & $\%$ & Average $\pm \mathrm{CI}$ \\
\hline \multicolumn{4}{|c|}{ Duration before enteral feeding(d) } \\
\hline$<1$ & 2 & 5.71 & \multirow{3}{*}{$2 \pm 0.8 j$} \\
\hline $1-2$ & 24 & 68.57 & \\
\hline$>2$ & 9 & 25.71 & \\
\hline \multicolumn{4}{|c|}{ Duration before nutritional autonomy } \\
\hline$<3$ & 2 & 5.71 & \multirow{3}{*}{$4.14 \pm 3.3 \mathrm{j}$} \\
\hline $3-5$ & 22 & 62.85 & \\
\hline$\geq 5$ & 11 & 31.42 & \\
\hline \multicolumn{4}{|c|}{ Type of breastfeeding at admission } \\
\hline None & 13 & 27.08 & \\
\hline Breastmilk & 14 & 29.17 & \\
\hline Artificial milk & 20 & 41.67 & \\
\hline Mixed milk & 1 & 2.08 & \\
\hline \multicolumn{4}{|c|}{ Digestive intolerance } \\
\hline Yes & 15 & 42.86 & \\
\hline No & 20 & 57.14 & \\
\hline \multicolumn{4}{|c|}{ Type of breastfeeding at discharge } \\
\hline Breastmilk & 10 & 43.48 & \\
\hline Artificial milk & 3 & 13.04 & \\
\hline Mixed milk & 10 & 43.48 & \\
\hline
\end{tabular}

On Table 3 is present the appearance of digestive intolerance according to the diet. New-borns had died before we could feed them, so they never received any milk.

Feeding with artificial milk and mixed breastfeeding was a risk of gastrointestinal intolerance $[R R=1.33(0.57$ $3.06)]$ but the association was not significant $(\mathrm{p}=0.36)$. Breastfeeding was a protective factor for the development of gastrointestinal intolerance, but the association was not significant in our case $[R R=0.75(0.32-1.72)](p=0.25)$.

Table 4 shows the hospital outcome of VLBWs. VLBW with a birth weight less than $1,000 \mathrm{~g}$ were 2.12 times more likely to die than those between 1,000 and 1,499 $\mathrm{g}$ $[R R=2.12(1.33-3.38)] p=0.005$. New-borns with gestational age less than or equal to 32 were 4.02 times more likely to die than those who had gestational age > $32[\mathrm{RR}=4.02(1.86-8), 70] \mathrm{p}=0.001$. There was no evidence of a significant association between digestive intolerance and VLBW outcome. There was no significant association between the type of milk received at the intake and its outcome.

Table 3: Appearance of digestive intolerance according to diet (type of milk).

\begin{tabular}{|lllllll|}
\hline Type of feeding & Yes & $\mathbf{N}=\mathbf{1 5}$ & No & $\mathbf{N}=\mathbf{2 0}$ & $\mathbf{P}$ & RR \\
\hline Artificiel and mixed & $\mathbf{N}$ & $\mathbf{\%}$ & $\mathbf{N}$ & $\mathbf{\%}$ & & IC 95\% \\
\hline Breastmilk & 10 & 67 & 11 & 55 & 0.36 & $1.33(0.57-3.06)$ \\
\hline
\end{tabular}

Table 4: Outcome of VLBW.

\begin{tabular}{|c|c|c|c|c|c|c|}
\hline \multirow{2}{*}{ Factors } & \multicolumn{2}{|c|}{ Dead } & \multicolumn{2}{|c|}{ Living } & \multirow[b]{2}{*}{$\mathbf{P}$} & \multirow{2}{*}{$\begin{array}{l}\text { RR } \\
\text { IC 95\% }\end{array}$} \\
\hline & $\mathbf{N}$ & $\%$ & $\mathbf{N}$ & $\%$ & & \\
\hline \multicolumn{7}{|c|}{ Birth weight (g) } \\
\hline$<1000$ & 11 & 85.71 & 2 & 14.29 & \multirow{2}{*}{0.005} & 2.12 \\
\hline $1000-1500$ & 14 & 38.24 & 21 & 61.76 & & $1.33-3.38$ \\
\hline \multicolumn{7}{|c|}{ Gestational age } \\
\hline$<=32$ & 25 & 70.97 & 9 & 29.03 & \multirow{2}{*}{0.001} & 4.02 \\
\hline$>32$ & 3 & 17.65 & 14 & 82.35 & & $1.86-8.70$ \\
\hline \multicolumn{7}{|c|}{ Place of delivery } \\
\hline Inborn & 19 & 50 & 19 & 50 & \multirow{2}{*}{0.57} & 1.20 \\
\hline Outborn & 6 & 60 & 4 & 40 & & $0.66-2.18$ \\
\hline \multicolumn{7}{|c|}{ Mode of delivery } \\
\hline Natural & 19 & 63.3 & 11 & 36.6 & 0.04 & 1.9 \\
\hline Caesarean & 6 & 33.3 & 12 & 66.6 & & $0.94-3.86$ \\
\hline \multicolumn{7}{|l|}{ Type of milk } \\
\hline Artificial milk & 7 & 35 & 13 & 65 & \multirow{2}{*}{0.53} & 0.98 \\
\hline Breastmilk & 5 & 35.71 & 9 & 64.29 & & $0.39-2.46$ \\
\hline \multicolumn{7}{|c|}{ Digestive intolerance } \\
\hline Yes & 5 & 33.33 & 10 & 66.67 & \multirow{2}{*}{0.54} & 0.95 \\
\hline No & 7 & 35 & 13 & 65 & & $0.38-2.41$ \\
\hline
\end{tabular}




\section{DISCUSSION}

\section{Prevalence}

We found a hospital prevalence of VLBW of $8.8 \%$. A higher prevalence of $9.9 \%$ was found in a study conducted by Ranaivo et al, from 2015 to 2016 at CHUGOB. ${ }^{7}$ Njom et al, in Cameroon found a proportion of $6 \%$, against the prevalence was $21 \%$ for Velaphi et al, in Johannesburg. ${ }^{8,9}$ In developed countries, Eric $\mathrm{C}$ et al, in the United States found a prevalence of $1.5 \% .^{10}$

A study by Khorshidi et al, in Iran in 2011, labeled a hospital prevalence of VLBW of $0.2 \% .^{11}$

A high prevalence was thus found in our study and that of African countries. It is linked to a precarious socioeconomic situation which has been demonstrated by the literature as being a factor favoring the occurrence of low birth weight. ${ }^{12}$ So, access to obstetric and neonatal care is limited in low-income countries, and at-risk pregnancies may be missed, delaying care. In addition, a maternal nutritional deficit linked to low financial power plays a role in the occurrence of low birth weight. ${ }^{13}$

\section{Nutrition}

The mean age of onset of enteral feeding in our study was $2 \pm 0.8$ days. A study conducted in Senegal in 2012 also found an average age of enteral feeding of $2.5 \pm 2.8$ days. In these contexts, parenteral nutrition is not available because of the lack of a suitable technical platform and its high cost. Hence enteral nutrition should be considered as soon as possible. ${ }^{5}$ In contrast, in developed countries, the introduction of enteral feeding is more delayed from the $96^{\text {th }}$ hour of life. ${ }^{14}$

We found that the average age of food self-sufficiency was 4 days. According to Faye PM et al, at the Albert Royer National Children's Hospital in 2016, it is 6.4 26.1 days. ${ }^{5}$ Such a result is explained once more by the absence of parenteral nutrition which requires an early start of enteral feeding thus allowing early infusion of polyionic solution. Hence the rapid acquisition of food autonomy.

Artificial milk was the most used at the beginning of enteral feeding in $41.66 \%$ of cases. In contrast, a study by Hamilton E et al showed that $72 \%$ of VLBWs received breast milk from either mother's milk or women's donations compared to only $28 \%$ for formula milk. ${ }^{15}$ This low use of breast milk at admission in our study is due to the lack of lactarium in the service and some practical constraints related to mother-child separation.

We found that feeding with artificial milk did not constitute a risk of gastrointestinal intolerance $[\mathrm{RR}=1.33$ (0.57-3.06)] $\mathrm{p}=0.36$. This finding differs from was reported in a Cochrane review in 2007 that a randomized trial of formula milk versus women's milk was highlighted, indicating a significant increase in the risk of occurrence of UNEC in children fed formula milk. ${ }^{16}$ This difference in result could be explained by the small size of our sample.

Breastfeeding is a protective factor for the development of digestive intolerance, but the association was not significant in our case. What distinguishes results from another study, in which the authors reported that the use of human milk compared to milk formulas is associated with a significant decrease in UNEC. ${ }^{17}$

Breastmilk is the ideal diet for the newborn, for the premature infant and especially for the VLBW. ${ }^{18,19}$

It has irreplaceable biological and nutritional qualities, reduces the incidence of ulcerative necrotizing enterocolitis and secondary infections, promotes digestive autonomisation, and contributes to the improvement of the neuro-developmental and sensory prognosis of the premature infant. ${ }^{18,20}$

WHO strongly recommends breastfeeding for VLBW in 2011. ${ }^{21}$ In developed countries, donor-derived female milk is an optimal alternative. ${ }^{22}$ In order for newborns to benefit from breast-milk feeding, the establishment of a lactarium or a milk bank should be considered neonatalogy services in Madagascar so that newborns can benefit from feeding through breast milk.

\section{Early outcome}

In our study, infants with a birth weight of less than 1,000 $\mathrm{g}$ were 2.12 times more likely to die than those with a birth weight greater than or equal to $1,000 \mathrm{~g}[\mathrm{RR}=2,12$ (1.33-3.38)] $\mathrm{p}=0.005$ (Table 4).

These results are similar to those found in several studies. The study by Mukherjee S et al, in India between 2014 and 2016 showed that high birth weight is statistically associated with surviva. ${ }^{7}$

Similarly, the study by Kabilan S et al. between 2016 and 2017, a mortality rate of $100 \%$ was observed for VLBWs with a birth weight of less than $750 \mathrm{~g}$ compared with $16.66 \%$ for those with a birth weight between $1.251 \mathrm{~g}$ and $1.500 \mathrm{~g}^{8}$

Larroque B et al, showed that low birth weight was associated with an increased risk of mortality. ${ }^{9}$ Worldwide, low birth weight is a major indirect cause of death. ${ }^{10}$ These newborns with low birth weight are a vulnerable group because of the risks they may incur. On the one hand, they are at risk of hypothermia, hypoglycemia, hypocalcemia, and on the other hand at risk of pulmonary complications with its processions, digestive, neurological and infectious complications. ${ }^{9}$

These complications are related to the immaturity of the organs because there is a relation between the degree of 
maturation and the birth weight. In addition, the lack of a technical platform for adequate management of extreme low birth weights contributes to this mortality.

In our study, the lower the gestational age, the greater the proportion of deceased VLBWs (Table 4). Newborns with a gestational age of $32 \mathrm{SA}$ or less in our score had a 4.02 times increased risk of dying $[R R=4.02$ (1.868.70)] $\mathrm{p}=0.001$. Several studies have confirmed this significant association. ${ }^{11,12,16}$ In the Badr et al series, the survival rate increases with gestational age. ${ }^{11}$ The degree of immaturity is a function of gestational age. The higher the gestational age, the more the different organs acquire a certain degree of maturity. ${ }^{12}$

Thus, in order to reduce the high mortality of newborns of VLBW and / or premature, their prevention is essential by a good monitoring of pregnancies.

We did not demonstrate a significant association between the presence of digestive intolerance and the fate of VLBW (Table 4). Contrary to the study by Ranaivo et al, who found that the absence of digestive intolerance gives more chance of survival. ${ }^{7}$ According to a Cochrane review written by Morgan $\mathrm{J}$ et al, UNEC is a major cause of morbidity and mortality among VLBWs. ${ }^{14}$ The gap between the size of our sample and that of the literature could be a limitation of our interpretation.

The use of artificial milk was not significantly associated with VLBW outcome (Table 4). The analysis result from The Cochrane Library revealed that there is no randomized controlled trial data to determine whether feeding preterm or low birth weight infants with infant formula versus breast milk affects growth, development or other clinically important outcomes. ${ }^{16}$

\section{CONCLUSION}

This study revealed that the hospital prevalence of VLBW has not decreased significantly in Antananarivo. The mortality observed is all the higher as the gestational age is far from the end and the birth weight is small. The use of artificial milk was not associated with digestive intolerance; it did not have a negative influence on the early fate of the new VLBW. Given the immediate unavailability of breast milk that would be ideal for the newborn, the alternative that is not disadvantageous is the adapted artificial milk.

Funding: No funding sources

Conflict of interest: None declared

Ethical approval: The study was approved by the Institutional Ethics Committee

\section{REFERENCES}

1. United Nations Children's Fund WHO. Low birth weight: country, regional and global estimates. New York: UNICEF. 2004:7. Available at: http//:apps.who.int/iris/bitstream/10665/.../92806383

27. Pdf. Assessed on $16^{\text {th }}$ May 2018.

2. Lemons J, Charles R, William O, Sheldon B, LuAnn P, Barabara J, et al. Very low birth weight outcomes of the National Institute of Child Health and Human Development Neonatal Research Network January 1995 through December 1996. Am Acad Pediatr. 2001;107:1-8.

3. Canbak Y, Silfeler I, Dorum BA, Kurnaz H, Dorum $\mathrm{S}$. The ratio of mortality and morbidity in very low birth weight in a public hospital. Turk Arch Pediatr. 2011;46:137-43.

4. Eric C, Ann R. Management and outcomes of very low birth weight. The $\mathrm{N}$ Engl J Med. 2008;358(16):1700-11.

5. Faye PM, Diagne-Guèye NR, Paraiso IR, Bâ A. Croissance pondérale postnatale des nouveau-nés de faible poids de naissance au service de néonatologie du centre hospitalier national d'enfants Albert Royer: Incidence du retard de croissance extra-utérin. J Pediatr Puéric. 2016;29:20-7.

6. Isayama T, Lee SK, Mori R, Kusuda S, Fujimura M, Ye XY, et al. Comparison of mortality and morbidity of very low birth weights infants between Canada and Japan. Pediatr. 2012;130(4):e957-65.

7. Ranaivo NAR, Tsifiregna RL, Ramananirina MZ, Ranosiarisoa ZN, Rajaonarison RHJ, Robinson AL. Facteurs influençant la survie des nouveau-nés de très faible poids de naissance au CHUGOB. Rev Malg Ped. 2018;1(1):8-17.

8. NjomNlend A, Zeudja C, Ndiang S, NgaMotaze A, Ngassam L, Nsoa L. Tendances évolutives de la mortalité néonatale des nouveau-nés de moins de $1500 \mathrm{~g}$ de 1998 à 2013 au centre hospitalier d'Essos, Yaounde, Cameroun. Arch Pediatr. 2016;23:895-8.

9. Velaphi SC, Mokhachane M, Mphahlele RM, BeckhArnold E, Kuwanda ML, Cooper PA. Survival of very-low-birth-weight infants according to birth weight and gestational age in a public hospital. S Afr Med J. 2005;95(7):504-9.

10. Eric C, Ann R. Management and outcomes of very low birth weight. The $\mathrm{N}$ Engl J Med. 2008;358(16):1700-11.

11. Khorshidi M, Nooshirvanpour P, Najafi S. Incidence of low birth weight in mazandaran province North Iran. Oman Med J. 2013;28:39-41.

12. Nair NS, Rao RS, Chandrashekar S, Acharya D, Bhat HV. Socio-demographics and maternal determinants of low birth weight: a multivariate approach. Indian J Pediatr. 2000;67(5):9-14.

13. Lepercq J, Boileau P. Physiologie de la croissance fœtale. EMCGynécologie Obstétrique. 2005(2):199208.

14. Morgan J, Bombell S, Guire W. Early trophic feeding versus enteral fasting for very preterm or very low birth weight infants. Cochrane Database Syst Rev. 2013;3:1-30.

15. Emily H, Cynthia M, Julie R, Sarah T. Early enteral feeding in very low birth weight infants. Early Human Develop. 2014;90:227-30. 
16. Henderson G, Anthony M, McGuire W. Formula milk versus maternal breast milk for feeding preterm or low birth weight infants. Cochrane Database Syst Rev. 2007;(4):1-54.

17. Millet C. Pathologies digestives et nutrition. EMCPédiatrie. 2012;7(2):1-8.

18. Rigourd V, Nicloux M, Hovanishian S, Giuséppi A, Hachem T, Assaf Z, et al. Conseil pour l'allaitement maternel. J Pediatrpuéric. 2018;31:51-74.

19. David HA, Paula GR. Fortification of human milk in very low birth weight infants (VLBW <1500 g Birth Weight). Clin Perinat. 2014;41(02):405-21.

20. Mandy BB, Richard AE. Neurodevelopmental outcomes and nutritional strategies in very low birth weight infants. Sem Fetal Neonat Med. 2017;22(1):42-8.

21. World Health Organization. Guidelines on optimal feeding of low birth-weight infants in low- and middle-income countries. ISBN. 2011. Available at: https://www.who.int/maternal_child_adolescent/docu ments/9789241548366.pdf?ua $=1$. Accessed on $16^{\text {th }}$ May 2018.

22. Eidelman AI, Shanler RJ, Johnston M, Landers M. Breastfeeding and the use of human milk. Pediatr Am Acad Pediatr. 2012;129(3):e827-4.

Cite this article as: Ranosiarisoa ZN, Ramananirina MZ, Tsifiregna RL, Ravelomanana L, Ravelomanana N. Nutritional management of very low birth weight at a hospital center of Antananarivo. Int J Reprod Contracept Obstet Gynecol 2019;8:4654-9. 